İdrar Örneklerinden Soyutlanan Escherichia coli Suşlarında Genişlemiş Spektrumlu Beta-Laktamaz Aktivitesinin ve Ertapenem Etkinliğinin Belirlenmesi

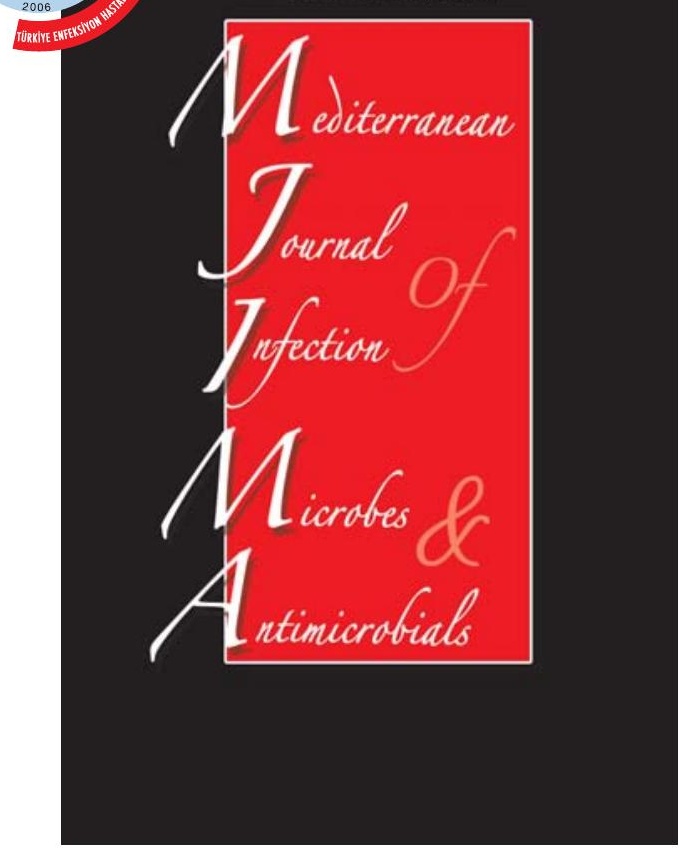

\title{
Extended-Spectrum Beta-Lactamase Activity and In Vitro Efficiency of Ertapenem among Escherichia coli Strains Isolated from Urine Samples
}

Yeliz ÇETINKOL ${ }^{1}$, Arzu ALTUNÇEKIÇ YILDIRIM² ${ }^{2}$ Fazilet ÖZENÇ ÇAKIR ${ }^{3}$

${ }^{1}$ Ordu Üniversitesi Tıp Fakültesi, Tıbbi Mikrobiyoloji Anabilim Dalı, Ordu, Türkiye

${ }^{1}$ Department of Medical Microbiology, Faculty of Medicine, University of Ordu, Ordu, Turkey

${ }^{2}$ Ordu Üniversitesi Tıp Fakültesi, Enfeksiyon Hastalıkları ve Klinik Mikrobiyoloji Anabilim Dalı, Ordu, Türkiye

2 Department of Infectious Diseases and Clinical Microbiology, Faculty of Medicine, University of Ordu, Ordu, Turkey

${ }^{3}$ Ordu Boztepe Devlet Hastanesi, Mikrobiyoloji Laboratuvarı, Ordu, Türkiye

${ }^{3}$ Laboratory of Microbiology, Ordu Boztepe State Hospital, Ordu, Turkey

\section{ÖZET}

Giriş: Üriner sistem enfeksiyonları, toplumda ve hastanede gelişen enfeksiyonlar arasında ilk sırada yer alan enfeksiyonlardır Escherichia coli bu enfeksiyonlarda en sık izole edilen etkendir. Yaygın antibiyotik kullanımıyla ilişkili olarak beta-laktamaz ve özellikle genişlemiş spektrumlu beta-laktamaz (GSBL) üreten suşların sayısı giderek artmakta ve gelişen antimikrobiyal direnç yüzünden morbidite-mortalite ve tedavi maliyetleri artmaktadır. Bu çalışmada mikrobiyoloji laboratuvarına gönderilen idrar örneklerinden izole edilen E. coli suşlarında GSBL aktivitesinin ve son yıllarda klinik kullanıma giren ertapenemin in vitro etkinliğinin araştırılması amaçlanmıştır.

Materyal ve Metod: Eylül 2012-Eylül 2013 tarihleri arasında Mikrobiyoloji Laboratuvarında üriner örneklerden izole edilen 346 E. coli suşu çalışma kapsamına alınmıştır. Örnekler rutin inceleme amacıyla \%5 Koyun Kanlı Agar ve Eosin Metilen Blue Agar besiyerlerine ekilmiş, $24-48$ saat $35^{\circ} \mathrm{C}$ 'de aerop ortamda inkübe edildikten sonra üreyen bakteri suşlarının identifikasyonları yapılmışıı. Bakteri tanımlanmasında konvansiyonel yöntemler yanında ViTEK2 (bioMerieux, Fransa) tam otomatize identifikasyon sistemi kullanılmıştır. Tanımlanan bakterilerin antibiyotik duyarlılık testleri de "Clinical and Laboratory Standards Institute (CLSI)" kriterleri esas alınarak VITEK2 sistemiyle değerlendirilmiştir.

Bulgular: İdrar örneklerinden izole edilen 346 E. coli suşundan 70 (\%20.2)'inin GSBL pozitif olduğu saptandı. E. coli suşlarında ertapeneme duyarlıık oranı \%97.4 olarak tespit edildi. Ayrıca, GSBL negatif E. coli suşlarının tamamı ertapeneme duyarlı bulu- 
nurken, GSBL pozitif E. coli suşlarından \%12.9'unun dirençli olduğu saptandı. GSBL pozitif ve negatif suşlar için ertapeneme duyarlılık oranları arasında istatistiksel olarak anlamlı fark bulundu $(p<0.05)$.

Sonuç: GSBL pozitif ve negatif $E$. coli suşlarının neden olduğu enfeksiyonların antimikrobik ajanlarla tedavisinde yüksek duyarlılık oranına sahip, ayrıca günde tek doz olarak kullanım kolaylığı getiren ertapenemin iyi bir alternatif seçenek olabileceğini düşünmekteyiz.

Anahtar kelimeler: Ertapenem, Escherichia coli, genişlemiş spektrumlu beta-laktamaz

Geliş Tarihi: 15.01.2014 • Kabul Ediliş Tarihi: 22.06.2014 • Yayınlanma Tarihi: 03.07.2014

\section{ABSTRACT}

Introduction: Urinary tract infections are the most common infections among community and hospital-acquired infections. Escherichia coli is the most frequently isolated pathogen of these infections. Despite the widespread use of antibiotics, especially beta-lactamase and extended-spectrum beta-lactamase (ESBL) producing strains continue to increase in number. Since these strains have evolved antimicrobial resistance, morbidity and mortality rates and treatment costs are increasing. The aim of this study was to investigate ESBL activity of $E$. coli strains isolated from the urine samples sent to microbiology laboratory, and in vitro efficacy of ertapenem which recently entered the clinical use.

Materials and Methods: A total of 346 E. coli strains isolated from urinary specimens sent to clinical microbiology laboratory between September 2012 and September 2013 were included in the study. The samples were inoculated in 5\% sheep blood agar and Eosin Methylene Blue Agar plates, and incubated in aerobic environment for $24-48$ hours at $35^{\circ} \mathrm{C}$ for routine examination. Besides conventional methods, VITEK 2 (bioMerieux, France) full automated system, was used for bacterial identification. Antibiotic sensitivity test of the identified bacteria was carried out by VITEK2 system, based on "Clinical and Laboratory Standards Institute (CLSI)" criteria.

Results: Seventy $(20.2 \%)$ of 346 E. coli strains isolated from urine samples were found to be ESBL producer. Of these $97.4 \%$ were sensitive to ertapenem and all ESBL negative E. coli strains were found to be susceptible to ertapenem. About $12.9 \%$ of ESBL positive E. coli strains were ertapenem-resistant. When we comparec sensitivity to ertapenem in ESBL positive and negative strains, the difference was statistically significantly $(p<0.05)$.

Conclusion: Ertapenem is believed to be a good alternative of antimicrobial agent for the treatment of ESBL positive and negative $E$. coli infections with high sensitivity ratio and ease of single daily dose.

Key words: Ertapenem, Escherichia coli, extended-spectrum beta-lactamase

Received: 15.01.2014 • Accepted: 22.06.2014 • Published: 03.07.2014

\section{Gíisiș}

Üriner sistem enfeksiyonları (ÜSE), toplumda ve hastanede gelişen enfeksiyonlar arasında ilk sırada yer alan enfeksiyonlardır. Escherichia coli bu enfeksiyonlarda en sık izole edilen etkenler arasındadır. Yaygın antibiyotik kullanımıyla ilişkili olarak beta-laktamaz ve özellikle GSBL üreten suşların sayısı giderek artmakta ve gelişen antimikrobiyal direnç yüzünden morbidite-mortalite ve tedavi maliyetleri artmaktadır.

GSBL enzimleri, 1980'li yıllardan beri yaygın antibiyotik kullanımının yarattığı seçici baskı sonucu ortaya çıkmış, sayı ve çeşit yönünden artarak tüm dünyada önemli bir sorun haline gelmişsir ${ }^{[1]}$. GSBL pozitif suşlar, hastane enfeksiyonlarının yanı sıra toplumda gelişen enfeksiyonlardan da artan sıklıkla izole edilmektedir. Özellikle toplumda gelişen ÜSE'lerden izole edilen $E$. coli suşlarında GSBL üretim oranı dramatik olarak artmıştır ${ }^{[2]}$. GSBL üreten bakterilerin neden olduğu enfek- siyonlarda risk faktörleri, uzun süre hastanede kalma, yoğun bakım ünitesinde yatma, cerrahi işlemler, sefalosporin ve aminoglikozid kullanımı olarak saptanmıştır. GSBL pozitif izolatlar tüm dünyada olduğu gibi ülkemizde de yaygındır. GSBL prevalansı özellikle geniş spektrumlu sefalosporinlerin klinik tedaviye girme zamanı ve yaygın kullanımıyla ilişkili olduğu için GSBL sentezleyen suş sayısı ülkeler, şehirler, hastaneler ve hatta aynı hastanedeki servisler arasında bile değişiklik göstermektedir ${ }^{[3]}$.

Ertapenem, günde tek doz kullanıma uygun, serum yarı ömrü ve etki süresi uzun bir karbapenemdir. Enterobacteriaceae üyeleri, Streptococcus pneumoniae ve birçok anaerop bakteri de dahil olmak üzere grampozitif ve gram-negatif bakterileri kapsayan bir etki spektrumu vardır. Ancak Pseudomonas aeruginosa, Acinetobacter spp., MRSA ve enterokoklara karşı etkinliği sınırlıdır. Komplike üriner sistem enfeksiyonları, int- 
raabdominal ve pelvik enfeksiyonlar, deri ve yumuşak doku enfeksiyonları ve toplumda gelişen pnömoni gibi birçok klinik durumda rahatıkla kullanılabilmektedir ${ }^{[4]}$.

Hastanede ve toplumda gelişen enfeksiyonların tedavisinde ciddi sorunlara yol açan GSBL üreten bakterilerin sıklıklarının düzenli olarak izlenmesi, antibiyotik direnç profilinin çıkarılması, ampirik tedaviyi yönlendirmede ve tedavi başarısında önemli yol göstericidir. Bu çalışmada mikrobiyoloji laboratuvarına gönderilen idrar örneklerinden izole edilen E. coli suşlarında GSBL aktivitesinin ve son yıllarda klinik kullanıma giren ertapenemin in vitro etkinliğinin araştırıması amaçlanmıştır.

\section{MATERYAL ve METOD}

Bu çalışma, Eylül 2012-Eylül 2013 tarihleri arasında Mikrobiyoloji Laboratuvarına gönderilen hastanede yatmakta olan veya polikliniklere başvuran hastalara ait üriner örneklerden (idrar örneği) izole edilen $346 \mathrm{E}$. coli suşu çalışma kapsamına alınarak yapılmıştır. Örnekler rutin inceleme amacıyla \%5 Koyun Kanlı Agar ve Eosin Metilen Blue Agar besiyerlerine ekilmiş, 24-48 saat $35^{\circ} \mathrm{C}$ 'de aerop ortamda inkübe edildikten sonra üreyen bakteri suşlarının identifikasyonları yapılmıştır. Bakteri tanımlanmasında konvansiyonel yöntemler yanında VITEK2 (bioMerieux, Marcy l'Etoile, France) tam otomatize identifikasyon sistemi kullanılmıştır. Tanımlanan bakterilerin antibiyotik duyarlılık testleri ve GSBL oranlarının belirlenmesi için de CLSI kriterleri esas alınarak VITEK2 sistemiyle değerlendirilmiştir. Otomatize VITEK2 sistemi GSBL direncini CLSI standartlarına uygun olarak saptamaktadır. Saptanan identifikasyon ve antibiyogram sonuçları retrospektif olarak değerlendirilmiştir. Bu çalışmada, E. coli suşlarında GSBL görülme oranları belirlenmiş, bu bakterilerin GSBL pozitif ve GSBL negatif suşlarının ertapenem duyarlılıklarındaki farkların istatistiksel değerlendirmesi SPSS 16.0 paket programında ki-kare testiyle yapıımış ve $p \leq 0.05$ değeri anlamlı kabul edilmiştir.

\section{BULGULAR}

İdrar örneklerinden izole edilen 346 E. coli suşundan 70 (\%20.2)'inin GSBL pozitif olduğu saptandı. Hastaların 186 (\%53.8)'sı erkek, 160 (\%46.2)'ı kadın olup, kadınlardan izole edilen E. coli suşlarında GSBL görülme sıklığı, erkeklerden izole edilenlere göre istatistiksel olarak anlamlı şekilde yüksek bulundu ( $p<$ 0.05). E. coli suşlarının tümünün ertapeneme duyarlılıkları incelendiğinde bu oran \%97.4 olarak tespit edil- di. Ayrıca, GSBL negatif E. coli suşlarının tamamı ertapeneme duyarlı bulunurken, GSBL pozitif $E$. coli suşlarından \%12.9'unun dirençli olduğu saptandı. GSBL pozitif ve negatif suşlar için ertapeneme duyarlılık oranları arasında istatistiksel olarak anlamlı fark bulundu $(p<0.05)$.

\section{TARTIȘMA}

Plazmidler aracılığıyla türler arasında aktarılabilen GSBL direnci tedavilerin yetersiz kalmasına, hastaların hastanede yatış sürelerinin uzamasına ve mortalite oranlarının yükselmesine yol açabilmektedir. GSBL pozitif suşlar hastanelerde ciddi salgınlar oluşturabilmektedir ${ }^{[5]}$. E. coli suşları arasında GSBL pozitiflik oranının artması klinikte uygulanan tedavi seçeneklerini sınırlamakta, hastanede yatan hastaların yatış süresini uzatmakta ve hasta başına düşen toplam maliyeti artırmaktadır $^{[6]}$. Ülkemizde yapılan çok merkezli bir çalışmada (HITiT-2) hastanede gelişen E. coli suşlarında GSBL pozitiflik oranı $\% 42$ olarak bulunmuştur ${ }^{[7]}$. Tunçcan ve arkadaşlarının yaptıkları diğer bir çalışmada bu oran \%38 olarak saptanmıştır ${ }^{[8]}$. Tüm dünyada GSBL oranlarının giderek yükseldiği ve bu oranların dünyanın farklı bölgelerinde farklı oranlarda gözlendiği belirlenmiştir. Çok merkezli bir çalışma olan MYSTIC çalışmasında, Doğu Avrupa hastanelerinde GSBL üreten bakterilerde belirgin bir artış olduğu ve $E$. coli'deki GSBL oranlarının Brezilya'da \%19.6, Amerika'da \%5 oranında olduğu gösterilmiştir ${ }^{[9]}$. Bizim çalışmamızda da idrar örneklerinden izole edilen 346 E. coli suşundan 70 (\%20.2)'inde GSBL pozitifliği saptanmış olup, bu oranlar ülkemizde ve dünyada daha önce saptanan GSBL pozitiflik oranlarıyla uyumludur.

Kuzucu ve arkadaşlarının yaptıkları bir çalışmada GSBL pozitif suşlarda ertapenem duyarıı̆ı̆ı \%98.6 olarak bulunurken, bu suşların \%76'sı idrar örneklerinden, \%8.6'sı yara sürüntüsünden izole edilmiştir ${ }^{[10]}$. Yıldırım ve arkadaşlarının çalışmasında ise idrar örneklerinden izole edilen E. coli suşlarında GSBL pozitiflik oranı \%20.2, ertapeneme direnç oranı \%2.7 olarak bulunmuştur ${ }^{[11]}$. Uyanık ve arkadaşları ise kan kültürlerinden soyutlanan GSBL pozitif ve GSBL negatif E. coli suşlarında ertapenem duyarlıığını \%100 olarak belirlemişlerdir ${ }^{[12]}$. Ülkemizde yapılan farklı çalışmalarda ertapenem direnç oranlarının \%0-3 arasında değişim gösterdiği bildirilmekle birlikte, son yapılan bazı çalışmalarda bu oranların biraz daha yükseldi- 
ği ve hatta \%10'lara kadar çıktığı belirtilmektedir ${ }^{[13-16]}$. Alhambra ve arkadaşları ÜSE'den izole edilen Enterobacteriaceae üyesi 482 bakterinin tümünün ertapeneme duyarlı olduğunu bildirmişlerdir ${ }^{[17]}$. Fuchs ve arkadaşları gram-pozitif ve gram-negatif 5558 klinik izolatta ertapenem ve imipenem aktivitesini değerlendirmişler, Enterobacteriaceae ailesinde ertapenem aktivitesinin imipenemden daha yüksek olduğunu bulmuşlardır ${ }^{[18]}$. Bizim çalışmamızda E. coli suşlarında ertapeneme duyarlılık oranı \%97.4 olarak tespit edildi. Ayrıca, GSBL negatif $E$. coli suşlarının tamamı ertapeneme duyarlı bulunurken, GSBL pozitif $E$. coli suşlarından \%12.9'unun dirençli olduğu saptandı. Çalışmamızı yapılan bu çalışmalarla karşılaştırdığımızda, saptanan ertapenem direnç oranlarının biraz yüksek olmakla birlikte uyumlu sonuçlar olduğu görülmüştür. Çalışmamızda laboratuvara gönderilen hastaların örnekleri değerlendirildiği için poliklinikten başvuran hastaların gerçekten toplumda gelişen enfeksiyonları yansıtıp yansıtmadığı tam olarak bilinememektedir. Bu durum çalışmamızın kısıtlayıcı faktörüdür.

Ertapenemin günde tek doz uygulanabilmesi, tedavi maliyetini azaltmakta ve tedavi uyumunu artırmaktadır. Ayrıca ayaktan tedavi edilen diyabetik ayak gibi enfeksiyonlarda ve osteomiyelit gibi uzun tedavi süresi olan enfeksiyonlarda uygulama kolaylı̆̆ı da sağlamakta-

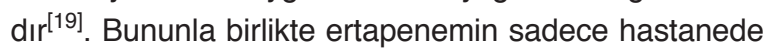
yatan hastalara ödenmesi önemli bir dezavantaj olarak karşımıza çıkmaktadır. Ertapenemin antianaerop etkinliği yanında, beta-laktamazların çoğuna da (TEM, SHV, GSBL vs.) dirençli olması diğer avantajı olarak görülmekte, bu da antibiyotiğin kullanım alanlarını genişletmektedir ${ }^{[20]}$. Ertapenemin, sistemik enfeksiyon bulgusu olan GSBL pozitif kökenlerle oluşan komplike idrar yolu enfeksiyonlarında kullanııması uygundur. Ayrıca alt üriner sistemde oluşan enfeksiyonların tedavisinde fosfomisin ve nitrofurantoinle de oldukça iyi sonuçlar alınmaktadır. Ülkemizde yapılan bir meta-analiz çalışmasında komplike olmayan ÜSE'li hastaların ampirik tedavisinde fosfomisin, nitrofurantoin ve oral üçüncü kuşak sefalosporinlerin uygun alternatif olabileceğini belirtmişlerdir[21]. Ayrıca Yaşar ve arkadaşları fosfomisinin GSBL pozitif ve siprofloksasine de dirençli $E$. coli izolatlarına bağlı gelişen üriner sistem infeksiyonlarının ayaktan tedavisine uygun bir antibiyotik olduğunu ortaya koymuşlardır ${ }^{[22]}$.
E. colınin neden olduğu ÜSE'lerin tedavisinde kullanılabilecek antibiyotikler çeşitli olmakla birlikte, artan direnç oranları nedeniyle özellikle yoğun bakım ünitesinde yatan hastalarda ampirik tedavi rejimi belirlenirken dikkatli olunmalıdır ${ }^{[23]}$. Dirençli suşların tedavisinde kullanılabilecek antibiyotik seçenekleri gün geçtikçe azalmaktadır. Giderek artan orandaki GSBL üretimi yüzünden morbidite ve mortalitede artış, tedavi başarısızlıkları ve komplikasyon riski ile sıklıkla karşı karşıya kalınmaktadır. Bu sebeple antibiyotik duyarlılık profillerindeki değişimlerin bölgesel olarak izlenerek direnç durumundaki değişimlerin ve GSBL oranlarının ortaya konması, uygunsuz antibiyotik kullanımının önlenmesi açısından oldukça önemlidir. Özellikle GSBL pozitif $E$. coli suşlarının neden olduğu enfeksiyonların antimikrobik ajanlarla tedavisinde yüksek duyarlılık oranına sahip ve günde tek doz olarak kullanım kolaylığı getiren ertapenem tedavi seçenekleri arasında yerini almıştır. Bu antibiyotiğin akılcı kullanılmasının elimizdeki gücün kısa sürede tüketilmesinin önünü keseceğini düşünmekteyiz.

\section{KAYNAKLAR}

1. Lautenbach E, Patel JB, Bilker WB, Edelstein PH, Fishman NO. Extended-spectrum beta-lactamase-producing Escherichia coli and Klebsiella pneumoniae: risk factors for infection and impact of resistance on outcomes. Clin Infect Dis 2001;32:1162-71.

2. Canton $R$, Novais A, Valverde A, Machado E, Peixe L, Baquero F, Coque TM. Prevalence and spread of extended-spectrum beta-lactamase-producing Enterobacteriaceae in Europe. Clin Microbiol Infect 2008;14(Suppl 1):144-53.

3. Mızrakçı Oğuz S, Arda B, Erdem HA, Uyar M, Tünger A, Sipahi $O R$, Ulusoy $S$. Anesteziyoloji ve reanimasyon yoğun bakım ünitesinde GSBL üreten Klebsiella pneumoniae ve Escherichia coli kolonizasyonu için risk faktörleri. Mikrobiyol Bul 2013;47:223-9.

4. Wexler HM. In vitro activity of ertapenem: review of recent studies. J Antimicrob Chemother 2004;53(Suppl 2):ii1121.

5. Sağlam D, Durmaz S, Kılıç H, Atalay MA, Erçal BD, Şarlı Ş, Perçin D. Kan kültürlerinden izole edilen Escherichia coli suşlarında genişlemiş spektrumlu beta-laktamaz sıkığı ve antibiyotik direnç paternleri. ANKEM 2011;25:2505 doi:10.5222/ankem.2011.250

6. Lautenbach E, Strom BL, Bilker WB, Patel JB, Edelstein $\mathrm{PH}$, Fishman NO. Epidemiological investigation of fluoroquinolone resistance in infections due to extended-spectrum beta-lactamase producing Escherichia coli and Klebsiella pneumoniae. Clin Infect Dis 2001;33:1288-94. 
7. Gür D, Hasçelik G, Aydın N et al. Antimicrobial resistance in Gram-negative hospital isolates: results of the Turkish HITIT-2 surveillance study of 2007. J Chemother 2009;21:383-9.

8. Tunçcan ÖG, Keten DT, Dizbay M, Hizel K. Hastane kaynaklı Escherichia coli ve Klebsiella suşlarının ertapenem ve diğer antibiyotiklere duyarlıı̆̆. ANKEM 2008;22:188-92.

9. Pfaller MA, Jones RN and the MYSTIC Study Group (Americas). MYSTIC (Meropenem Yearly Susceptibility Test Information Collection) results from the Americas: resistance implications in the treatment of serious infections. J Antimicrob Chemother 2000;46(Suppl T2):25-37.

10. Kuzucu Ç, Yetkin F, Görgeç S, Ersoy Y. Genişlemiş spektrumlu beta-laktamaz üreten Escherichia coli ve Klebsiella spp. suşlarının ertapenem ve diğer karbapenemlere karşı duyarlııklarının araştıııması. Mikrobiyol Bul 2011;45:2835.

11. Yıldırım F, Yaşar KK, Şengöz G, Sandıkçı S, Nazlıcan Ö. Ertapenem. Komplike üriner sistem enfeksiyonları için yeni bir antibiyotik seçeneği. Zeynep Kamil Tıp Bülteni 2009;40:17-21.

12. Uyanık MH, Hancı H, Yazgı H, Karameşe M. Kan kültürlerinden soyutlanan Escherichia coli ve Klebsiella pneumoniae suşlarında GSBL sıklığı ve ertapenem dahil çeşitli antibiyotiklere in-vitro duyarlılıkları. ANKEM 2010;24:86-91.

13. Betriu C, Salso S, Sancez A, et al. Comparative in vitro activity and the inoculum effect of ertapenem against Enterobactericeae resistant to extended-spectrum cephalosporins. Int J Antimicrob Agents 2006;28:1-5.

14. Livermore DM, Oakton KJ, Carter MW, Warner M. Activity of ertapenem (MK-0826) versus Enterobacteriaceae with potent beta-lactamases. Antimicrob Agents Chemother 2001;45:2831-7.

15. Mody RM, Erwin DP, Summers AM, Carrero HA, Selby $E B$, Ewell AJ, Moran KA. Ertapenem susceptibility of extended spectrum beta-lactamase-producing organisms. Ann Clin Microbiol Antimicrob 2007;6:1-6.

16. Paterson DL, Rossi F, Baquero F, Hsueh PR, Woods GL, Satishchondran V, Snyder TA, Harvey CM, Teppler $H$, Dinubile MJ, Chow JW. In vitro susceptibilities of aerobic and facultative gram-negative bacilli isolated from patients with intra-abdominal infections worldwide: the 2003 Study for Monitoring Antimicrob Resistance Trends (SMART). J Antimicrob Chemother 2005;55:965-73.

17. Alhambra A, Cuadros JA, Cacho J, Gómez-Garcés JL, Alós Jl. In vitro susceptibility of recent antibiotic-resistant urinary pathogens to ertapenem and 12 other antibiotics. $J$ Antimicrob Chemother 2004;53:1090-4.

18. Fuchs $P C$, Barry $A L$, Brown $S D$. In vitro activities of ertapenem (MK-0826) against clinical bacterial isolates from 11 North American Medical Centers. Antimicrob Agents Chemother 2001;45:1915-8.

19. Mody RM, Erwin DP, Summers AM, et al. Ertapenem susceptibility of extended spectrum beta-lactamase-producing organisms. Ann Clin Microbiol Antimicrob 2007;6:1-6.

20. Aldridge KE. Ertapenem (MK-0826), a new karbapenem: comparative in vitro activity against clinically significant anaerobes. Diagn Microbiol Infect Dis 2002;44:181-6.

21. Tasbakan MI, Pullukcu H, Sipahi OR, Yamazhan T, Arda $B$, Ulusoy S. A pooled analysis of the resistance patterns of Escherichia coli strains isolated from urine cultures in Turkey: a comparison of the periods 1997-2001 and 2002-2007. Turk J Med Sci 2011;41:557-64.

22. Yaşar KK, Pehlivanoğlu F, Şengöz G. Alternatif tedavi seçeneği olarak fosfomisinin komplike üriner sistem infeksiyonlarından izole edilen GSBL pozitif Escherichia coli suşlarına etkinliği. ANKEM 2011;25:12-6.

23. Işıkgöz Taşbakan M. Yoğun Bakımda Sorunlu Enfeksiyonlarda Tedavi ve Kontrol: MDR Enterobacteriaceae'nın neden olduğu üriner sistem enfeksiyonları. EKMUD 2013 BILIMSEL PLATFORMU. 2013:27-9.

\section{Yazışma Adresi /Address for Correspondence}

\section{Dr. Yeliz ÇETINKOL}

Ordu Üniversitesi Tıp Fakültesi Tıbbi Mikrobiyoloji Anabilim Dalı Ordu, Türkiye

E-posta: dryelizcetinkol@gmail.com 